\title{
DEVELOPING E-LEARNING SYSTEM TO SUPPORT VISUAL IMPAIRMENT DURING COVID-19 PANDEMIC
}

\author{
Piya Techateerawat \\ Engineering Faculty, Thammasat University, Thailand
}

\begin{abstract}
E-learning is a common tool to support the education in variety of scenarios. As the education content can be prepared by the group of specialists, but the skilled teachers are limited in remote area. Also, the contents in most curriculum are planned to distribute to limited skilled people. The gap of education can be full-filled with E- learning system. However, the conventional E-learning is high cost system and not appropriated for rural area. Also, opensource system is complicated to implement and configure in dedicated curriculum. This research is proposed the customized design of E-learning system for supporting visual impaired student with dynamic design during Covid-19 pandemic. The limitation has challenged the research to sharing and testing among the stakeholders. The system is designed and implemented from actual requirements from teachers and students in university level. As a result, the result show student involvement and deliver more content and knowledge to the visual impaired students. The feedback from actual usage also is evaluated.
\end{abstract}

\section{KEYWORDS}

E-learning, Android, Visual Impaired, Covid-19.

\section{INTRODUCTION}

Electronic learning (E-learning) is a general system to support the learning process and assist the content delivering to the specified learner. The key features of E-learning are to let learner access contents promptly with less constraints e.g. remote area, limited time, lack of teacher and large number of learners. Since network performance and equipment are easily access currently, a number of learners' request more of E-learning system. Also, learners expect to use E-learning for knowledge sharing and on-demand contents.

This paper shows the customized solution of E-learning system that can be implemented in adaptive content with specified need (visual impaired students) The solution also can be applied to other scenarios for other organizations.

\section{E-LEARNING SYSTEM}

E-learning is shown as critical system for content sharing in business, research and academic. Since the market share of E-learning system reached $\$ 2$ trillions in 2001, many organizations implement the system for accessible and extra class support [1,2]. 
The main benefit of E-learning system is cost effective, flexibility, accessibility and content distribution. As the system are content centralized and using the technology platform for access anywhere-anytime. Then overall, it reduced the cost of staff, operation task and open the opportunity to more people [3]. It also adds more features that can provide online chat, AI enquiry, reminder, online quiz and content suggestions.

In general, large system is approaching with framework [4-5]. As developing time can be reduced significantly by using the built-in library. The security is conformed by the framework library as well as updating regularly with framework update. The important key is maintenance as framework using the standard model following with guidance.

The one of challenge of implementing E-learning is cost that increased 83 percent from 19982003 [6]. This is a struggle for many organizations especially in education system. However, the need of E-learning also pushes to one of the largest share markets [7]. For, specific small organization and limited budget company are difficult to access to the commercialized platform as well as the open source system also required the skilled person to configure and understand that need follow the scheme of open source package.

\section{FRAMEWORK}

Android framework is a structure that prepare for programmer to develop application. Adobe Illustrator and Figma are the of tools to design on UI and character based. SQLite is use for database of quiz and content storage. This assist for both user and backend side to communicate and interact and share contents over the network. Most of Android framework is based on JDK model, this scheme let programmer customize the framework to meet the requirement by using the universal programming language and layout organization that is compatible to designated devices. Also, most of the framework is based on open source, so it can minimize the cost of license and maintenance.

The advantage of using this framework is let the structure more robust and more secure from the prepared package compared to developing from bare bone. In addition, the framework has prepared the libraries and themes for developer to choose and apply. So, implementation can be rapid and more convenience to meet the requirement.

SQLite provides the up-to-date content structure that can add, delete and modify the content of application on the fly. These support the upcoming content update from the education curriculum. The special request is also to add the simple design features. The project designs the main character model of the simple page and support the handle the flexible of mobile device. This has been focussed for visual impaired student to handle the learning by themselves.

\section{Planning \& Development}

This E-learning system is based on the actual case from Thammasat University. The group of students and teacher in 2020 is based on the research. The development and evaluation are also based on the actual activity that interacts with students.

The design must be compatible to the new mobile devices (e.g. smart phone and tablets). The contents in each screen should be simplified with one main idea. 
The purpose of this E-learning system is to support the actual class and student has sufficient knowledge in using computer technology. The requirement and design of this system is survey from in-class students.

As this system need to support visual impaired students, the UI has brainstorm with the user and concluded the need to use the text-to-speech module. As text-to-speech has been developed for support need and assisted to deliver contents to audience [8] as shown in Fig 1. The method has been developed with support new equipment and software [9] as shown in Fig 2. In this system, all stakeholders are discussed in focus group and need to balance between instructor, student and family who support the student with lead to use the API to support the main content similar to strategy in fig 3 [10]. As a result, students are required to access to most standard contents as deliver in actual classroom.

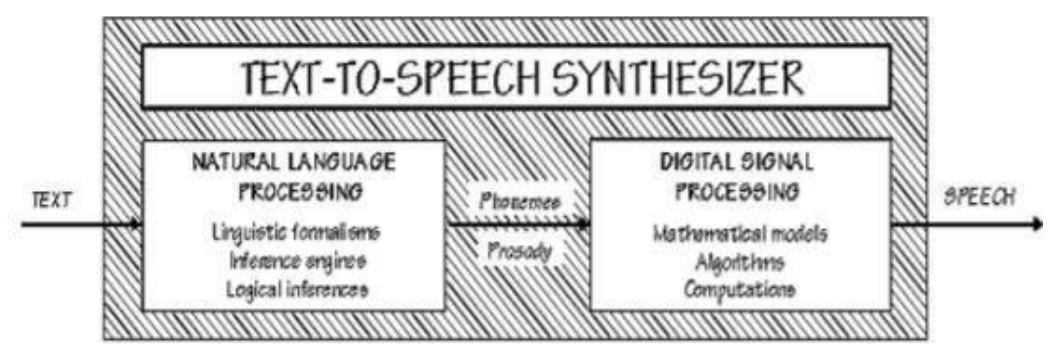

Fig. 1. Text-to-speech [8]

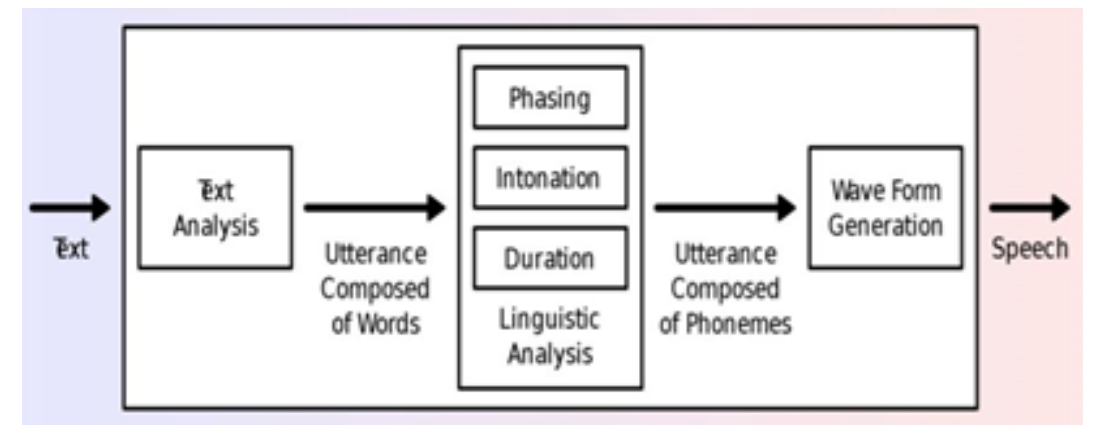

Fig. 2. Text-to-speech System [9]

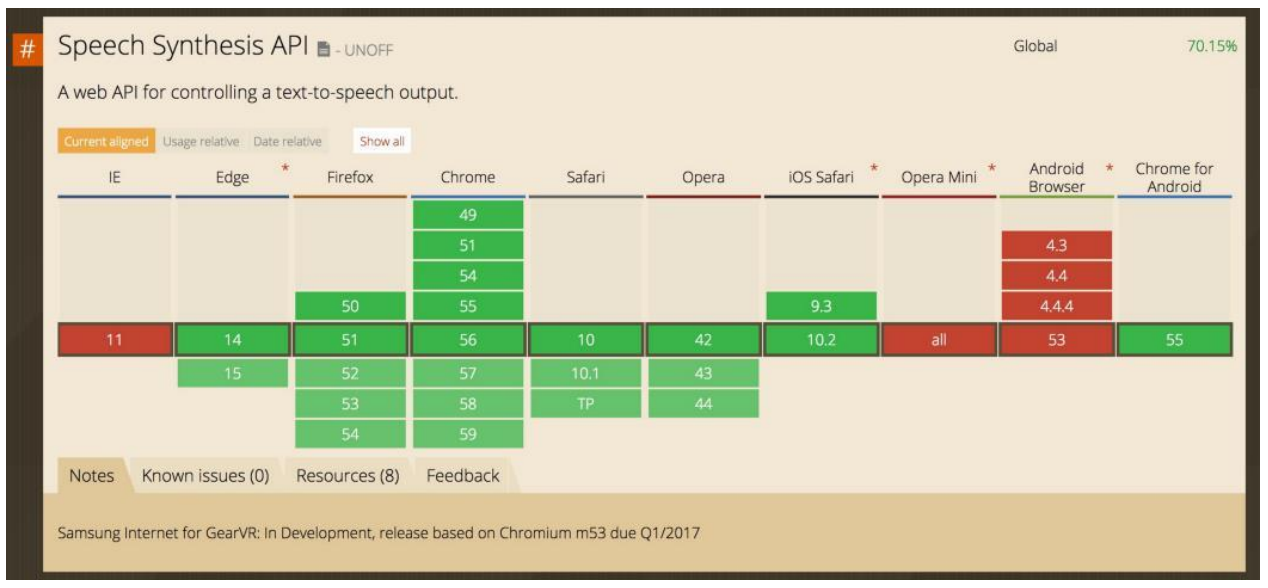

Fig. 3. Text-to-speech API support [10] 


\subsection{Requirement}

- The system must be convenient for visual impaired student or family to apply and access.

- Students which do not enrol may apply and register for the interest class.

- Every user can browse the contents in subject.

- The interface should be kids friendly.

- The objective must follow the core curriculum.

- The quiz must the task of activities in the class.

- The flow of application should let the student feel enjoy.

\subsection{Application Design}

This application is focused to deliver standard content to visual impaired students. As all stakeholder discussed in planning phase. The structure has been designed to support the need of all stakeholders. The ER diagram are also support from the need as shown in fig. 4. Next, the user interface is also break into small step for user to follow step-by-step guideline which replaced overall view information in modern design as shown in Fig. 5. Also, the main contents are brought to highlight focus which in main step e.g. lecture in audio file format and put in main focus of application and ready-to-play as shown in Fig 6.

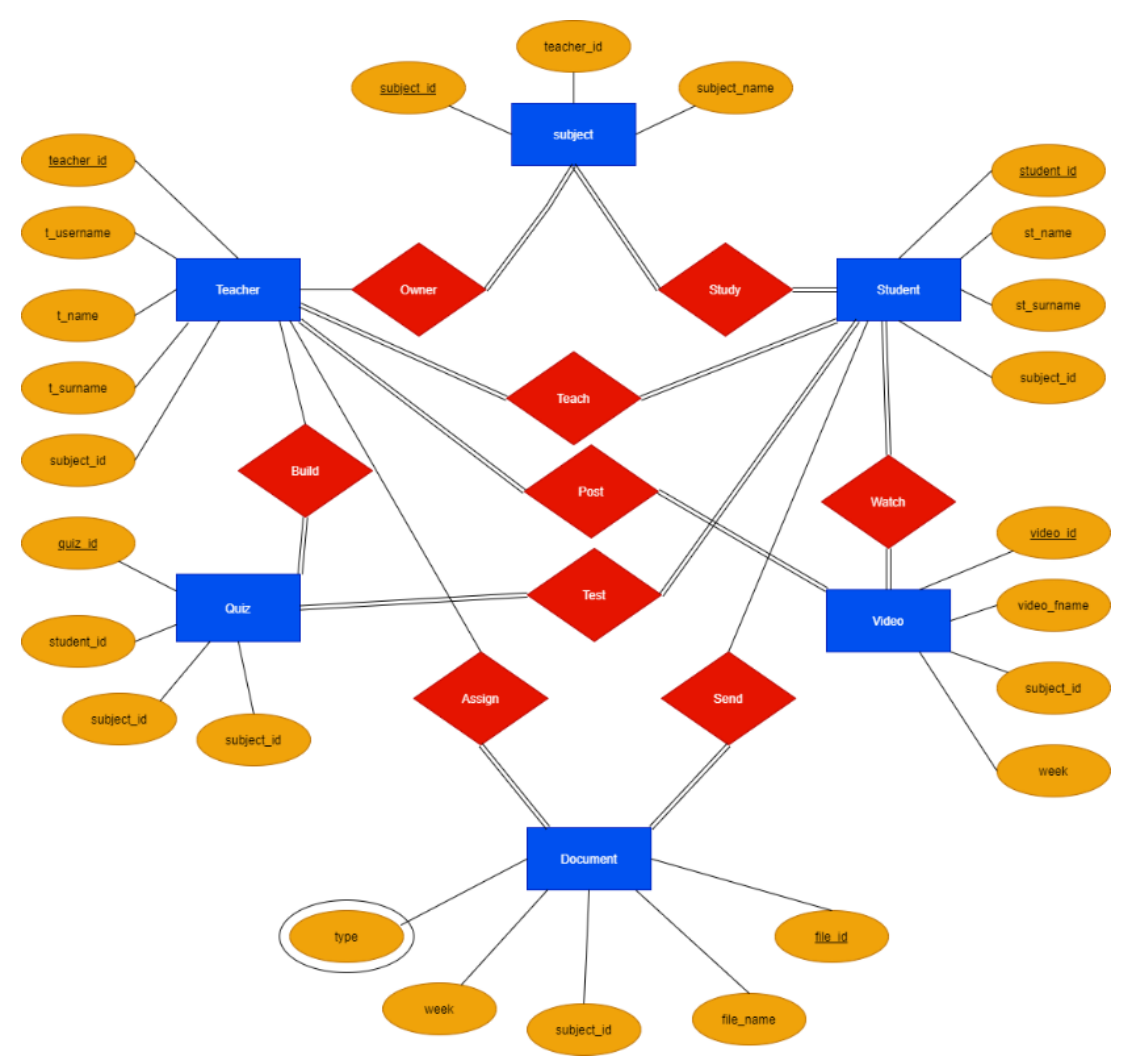

Fig. 4. ER Diagram 
pa317

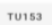

Fig. 5. Simple Content Design

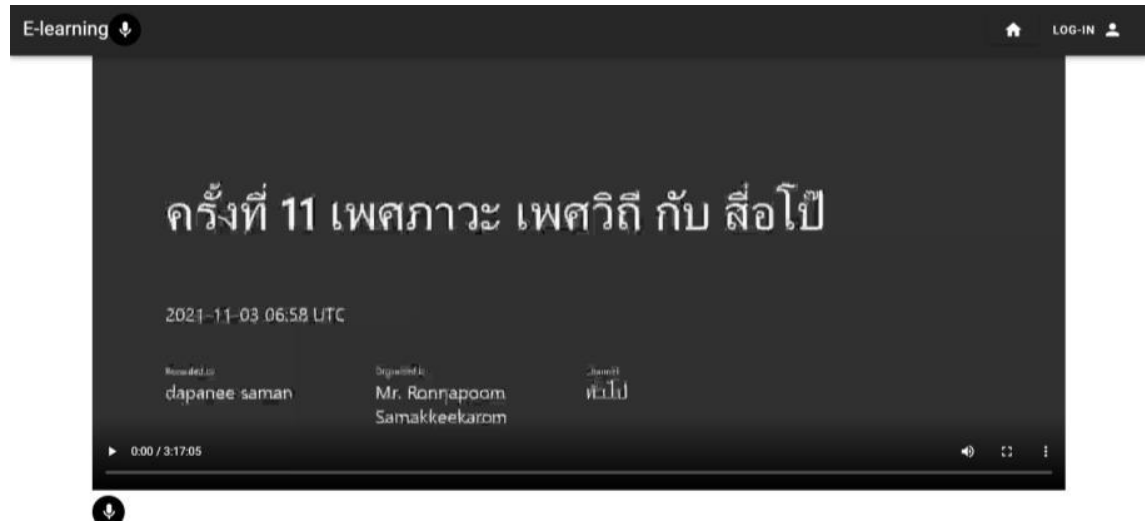

Fig. 6. Main Content are prioritized in audio format.

In quiz section, the quiz is based on the learning knowledge by pulling up the question from SQLite and arrange by the selected topics. When the user finishes the quiz, simple mark output is given. The quiz allows the user to re-do in the case the gain the understanding. Fig 7 shows the instructor mode that teacher can create the quiz in standard mode to support all class students. However, fig 8 shows that in visual impaired student has quiz in text-to-speech and use voice command to do the quiz.

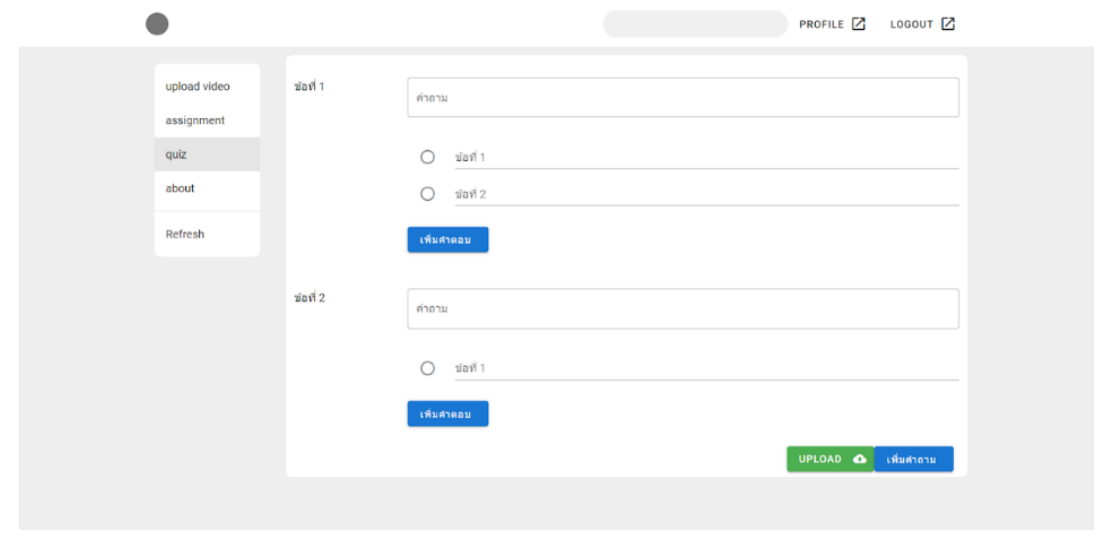

Fig. 7. Quiz preparation for instructor. 


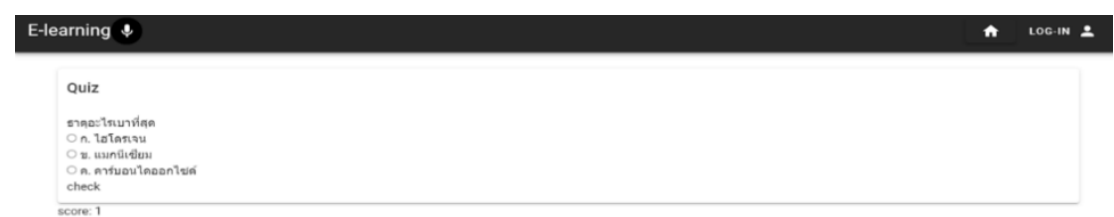

$(9$

Fig. 8. Quiz mode with voice command.

In quiz section, the quiz is based on the learning knowledge by pulling content from SQLite and using Genymotion to adjust the final result.

\section{RESULT}

The result of system is based on the actual testing in university students from Thammasat University. The group of visual impaired students are using this application along with class study and giving the test result and feedback as follows:

Administrator mode:

- Log-in to the system.

- Registering to the system.

- Access to E-learning contents \& downloadable contents.

- Some E-learning subject provide optional quiz.

- Search function.

- Forum for learner to share/discuss knowledge.

- File organization Add, Modify, Delete.

- Profile management.

- History organization (Review Content).

User mode:

- Topic selective.

- Content Summary

- Quiz

- Simple UI

- Design from user requirements.

The test result is based on the given time allocation of teacher to the students where the two weeks allocation on everyday task. The average time per slot is 88 minutes as shown in table 1 . Also, the support family also given the involvement and provide the feedback result for overall usage as shown in table 2 . 
Table 1. Summation of Usage Time

\begin{tabular}{|c|c|c|}
\hline & Male & Female \\
\hline $\begin{array}{c}\text { Average usage per } \\
\text { week }\end{array}$ & 9 & 9.7 \\
\hline $\begin{array}{c}\text { Average Time per } \\
\text { usage in class } \\
\text { (minutes) }\end{array}$ & 82 & 94 \\
\hline $\begin{array}{c}\text { Willing to continue to } \\
\text { use. }\end{array}$ & $95.71 \%$ & $97.5 \%$ \\
\hline $\begin{array}{c}\text { Average time per } \\
\text { usage at home } \\
\text { (minutes) }\end{array}$ & 58 & 64 \\
\hline
\end{tabular}

Table 2. Feedback Result

\begin{tabular}{|l|c|c|}
\hline \multicolumn{1}{|c|}{$\begin{array}{c}\text { Feedback (out of } \\
\text { 5) }\end{array}$} & Average & SD \\
\hline Quality of content & 3.95 & 0.1 \\
\hline $\begin{array}{l}\text { To support the class } \\
\text { knowledge }\end{array}$ & 3.95 & 0.1 \\
\hline Quality of application & 3.93 & 0.15 \\
\hline $\begin{array}{l}\text { Effective to learning } \\
\text { process }\end{array}$ & 3.97 & 0.07 \\
\hline
\end{tabular}

\section{DISCUSSION}

As this system is created based on the actual user (visual impaired students) requirement and reviewed by the same group student, our purpose is to gain more contribution of student. The objective is gaining more attention and support the in-class education.

As shown in Table 1, our objective is to evaluate the contribution of learner. As the learners does not intention to use the E-learning before this research. To motivate learners to contribute the new learning tools are shown in visual impaired students. The result also shows the continuous of the involvement for all study period in both school and home. This usage time includes both quiz and learning content based on 2020 students.

Manyinvolvements also require network traffic and computer resource. With this need, in our research has a large scale of computer resource in research lab. However, in real case, the system requires implementation resource in the organization. Therefore, with limited resource and recent technology, cloud server is suggested for the proposed system.

The quality from feedback is shown as above average due to the design and requirement of their choices, however they suggest that the improvement on the next version of application would be expected.

Overall, the customized system shows the significant improved in main objective of E-learning system. This also provides the solution that new trend of users needs the information in their own need format and their own need. The alternative solution is served their task achieved in this area. 


\section{Conclusion}

E-learning is challenged in every organization to customize for appropriate for each organization. The difference in objective, members' background and knowledge leads to different expectation. The customization system is a solution with a high cost of out-of-the-box software.

This paper suggest the customized E-learning system based on Android framework. The specific learning group are based visual impaired students. The features of this system are content sharing, online quiz and feedback system to the responding teacher in school. The implementation of deployed system is based on user's requirement that tend to meet with expectation.

The trend of user involvement is improving the participation in most of area especially support special need students.

\section{ACKNOWLEDGEMENTS}

We would like to thank Faculty of Engineering, Thammasat University, Thammasat University, Optical and Quantum Communication Research Lab and National Research Council of Thailand.

\section{REFERENCES}

[1] Cisco Systems, Cisco Systems IQ Atlas, Cisco, 2001.

[2] K. Fry, "E-learning markets and providers: some issues and prospects", Education + Training, Vol. 43 No. 4/5 pp. 233-9, 2001.

[3] S.M. Furnell, P.D. Onions, U. Bleimann, U. Gojny, M. Knahl, H. F. Roder and P.W. Sanders, "A security framework for online distance learning and training", Internet Research: Electronic Networking Applications and Policy, Vol. 8 No. 3, pp. 236-42, 1998.

[4] S. Alexander, "E-learning developments and experiences", Education + Training, Vol. 43 No. 4/5 pp. $240-8,2001$.

[5] S.H. Garrison and D.J. Borgia, "Using an Internet based distance learning to teach introductory finance", Campus-Wide Information Systems, Vol. 16 No. 4, pp. 136-9, 1999.

[6] D. Lance, "Venture captial viewpoints and E-learning futures", The Business of E-learning: Bringing Your Organization in the Knowledge Economy, Univeristy of Technology Sydney, 2000.

[7] P. Henry, "E-learning Technology, Content and Services", Education + Training, Vol. 43 No. 4, pp. 249-55, 2001.

[8] Itunuoluwa Isewon, Jelili Oyelade, Olufunke Oladipupo. "Design and Implementation of Text To Speech Conversion for Visually Impaired People" CORE, 2021.

[9] Raiyetunbi, Oladimeji Jude, Ayeh Emmanuel. "An Interactive Cloud Based User Oriented, Dynamic and Intelligent Text-To-Speech Module" Easpublisher, 2021.

[10] Wittawat Patcharinsak. "Conversation App with Web Speech API" konoesite.com. [Online]. Available: https://konoesite.com/สรา-conversation-app-ง่ายๆด้วย-web-speech-api- be54db5505f4. [Accessed: November. 9, 2020].

\section{AUTHORS}

Piya Techateerawat is a lecturer of Computer Engineering at Thammasat University. He received his B.Eng. from University of New South Wales, Australia with Honors in 2004. He continued his PhD study at Royal Melbourne Institute of Technology University, Australia, where he obtained his PhD in Wireless Sensor Network Security. His current interests involve applications of Sensor Network, Security and Quantum Cryptography.

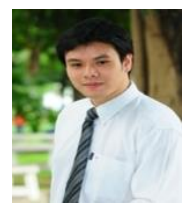

(C) 2021 By AIRCC Publishing Corporation. This article is published under the Creative Commons Attribution (CC BY) license. 